may be convenient for us to repeat certain facts observed by us in reference to the conditions tending to the elimination by the cow of bovine tubercle bacilli in her milk; facts in our opinion of such importance that they formed the subject of our Third Interim Report.

Bovine tubercle bacilli are apt to be abundantly present in milk as sold to the public when there is tuberculous disease of the udder of the cow from which it was obtained. This fact is, we believe, generally recognized though not adequately guarded against. But these bacilli may also be present in the milk of tuberculous cows presenting no evidence whatever of disease of the udder, even when examined post mortem. Further, the milk of tuberculous cows not containing bacilli, as it leaves the udder may, and frequently does, become infective by being contaminated with the faeces or uterine discharges of such diseased animal. We are convinced that measures for securing the prevention of ingestion of living bovine tubercle bacilli with milk would greatly reduce the number of cases of abdominal and cervical gland tuberculosis in children, and that such measures should include the exclusion from the food supply of the milk of the recognizably tuberculous cow, irrespective of the site of the disease, whether in the udder or in the internal organs.

\section{SANATORIUM TREATMENT OF TUBERCULOSIS.} The Welsh Memorial Scheme.

IN September last a conference of leading Welshmen was held at Shrewsbury to decide upon the form which the national memorial to the late King should take. On the proposal of Mr. David Davies, M.P. for Montgomeryshire, it was unanimously agreed to inaugurate a campaign against tuberculosis in the Principality. Mr. Davies himself led off with a subscription of $£ 25,000$. An executive com. mittee was appointed, with Mr. Davies as Chairman, and included the following, among other members: Lord Kenyon (Treasurer), Lord Glenesk, Colonel Cornwallis West, Dr. E. D. Evans (Wrexham), Mr. Lynn Thomas (Cardiff), Mr. J. E. Greaves (Lord Lieutenant of Carnarvonshire), Lady St. Davids, Mr. Haydon Jones, M.P., the Lord Mayor of Cardiff, the Mayor of Swansea, Lord Mostyn, and Dr. J. Robinson (Chairman of Health Committee, Cardiff Corporation). During the last eight months the campaign has been prosecuted with vigour, and nearly $£ 200,000$ has been received.

The Executive Committee of the Memorial Fund outlined a plan of campaign, embracing (1) educational propaganda by means of lectures and a travelling exhibition, (2) machinery for early detection of the disease, for example, by means of dispensaries or clinics, (3) sanatorium treatment for incipient cases and hospital or other treatment for advanced cases, and (4) after-care of discharged patients. The movement had gone thus far when the Chancello: of the Exchequer introduced his Insurance Bill. The tuberculosis clauses of the bill will naturally affect the policy of the Welsh campaign. The Executive Committee has drafted an amendment to the Insurance Bill which proposes that Wales and Monmouthshire shall be treated as a single administrative unit for the purpose of tuberculosis, and that the Edward VII Memorial Association shall be incorporated by charter and made a thoroughly democratic body, containing on its council representatives of county and county borough councils, the local Health Committees, the medical profession, and the subscribers to the fund. This scheme has been approved by the Welsh members of Parliament of all parties, and will immediately be laid before the Chancellor of the Exchequer by a deputation from them. In the meantime some confusion has been caused in the public mind by the constant use of the term "sanatorium" in the bill without anything to indicate that more than buildings are intended. The Welsh Committee is particularly anxious that the educational propaganda shall not be lost sight of. The claims made for tuberculin has raised a further question upon which the Welsh Committee has obtained the following reasoned statement defining in non-technical language the part which the sanatorium might be expected to play in an organized campaign :-

\section{Statement}

The Value of Sanatorium Treatment.

The public has formed a wrong impression of the value of sanatorium treatment, for it has not grasped the facts which prove that, in many cases, owing to the severity of the disease present, it must be useless; that in a few instances it is actually harmful; and that in many cases this method of treatment need not be carried out at an institution. Again, a number of people are under a misapprehension as to the meaning of sanatorium treatment. In many quarters it is considered to be synonymous with an existence under open-air conditions together with an excessive supply of nourishing food. Fresh air and food play an important part it is true, but the cardinal factor in the treatment is the constant and skilled regulation of the amounts of rest and exercise prescribed from day to day for each individual patient.

In order that these misapprehensions may be cleared away it is necessary to point out what takes place during the arrest of consumption in a given patient, and what are the principles of treatment. Consumption, as is well known, is due to the presence of minute organisms, called tubercle bacilli, in the lung. The only protection we have against these invaders is what may be termed comprehensively the defensive forces of the body. What these forces are we do not exactly know; but they have representatives in the blood and other fluids of the body, the tissue cells, the blood cells, etc. There is no drug which has a specific action upon tuberculosis. The vaccine known as tuberculin has a specific action, but there are a number of limitations to its power; one which may be mentioned here is that in many cases of consumption we have to deal not only with the tubercle bacillus, but also with other organisms against which tuberculin exerts no protective action.

The defensive forces of the body successfully combat and defeat the tubercle bacillus in an overwhelmingly large proportion of cases. That this is so is shown by the result that practically every man or woman over 35 bears evidence-available after death-of having suffered from tuberculosis. In the vast majority of these cases the tubercle bacillus has been routed, and this even without the individual ever knowing that he has contracted the disease.

What determines whether the defensive forces or the bacilli are to prove victorious? Naturally the defensive forces must be put in the best possible condition to fight. They require a constant supply of pure fresh air. Wind should also be avoided, as it increases the tendency to cough. Again, the defensive forces require a proper supply of good nourishing food with sufficient fatty food, such as milk, cream, butter, potatoes, etc., together with a careful regulation of the digestive processes.

These requirements do not, of course, in themselves necessitate a sanatorium, but, in the majority of cases amongst the working classes, it is difficult to provide them except in such an institution.

The chief reason which makes treatment in an institution a necessity is the need for constant supervision. This can only be explained by a consideration of certain pathological processes. The bacilli manufacture a poisoncalled tuberculin. This poison has a local effect on the lung in which they are present, causing destruction of tissue and so leading to cough, expectoration, blood spitting, and the signs detected by the stethoscope. The local action of the poison also stimulates a response from the local defensive forces. A more important fact is that some of the poison manufactured by the bacillis is absorbed by means of the lymph stream into the general circulation of the blood. If this poison in the blood stream is in excess of the powers of the defensive forces of the body to deal with, it leads to lassitude, loss of appetite, loss of weight, sweating and fever. If the dose of poison is a small one, the defensive forces of the body are stimulated to attack the bacilli. They go to the seat of conflict, surround the bacilli, and as the result of repeated stimulation by further small doses of poison eat up the weakened bacilli, and so in time arrest the disease. If the dose of poison is a larger one than the defensive forces can deal with, the latter are overpowered; the bacilli are left in command, multiply, cause the disease to spread in the lung, and pour out more poison, which, as already said, leads to fever, sweating, loss of weight and appetite, and all the distressing symptoms of advancing consumption.

Treatment must obviously be directed then to keep the dose of poison absorbed from the diseased area into the blood at such an amount that it stimulates and does not 
paralyse the defensive forces of the body on which we are so dependent.

The amount of poison absorbed depends in large part upon the amount of lymph and blood which goes through the diseased portion of the lung in a given time. A larger quantity of lymph and blood must automatically sweep out a larger quantity of poison. The quantity of lymph and blood which goes through the lung in a given time depends largely on the physiological law that the more work an organ has to do the greater must be its supply of blood and lymph. If a lung moves more than usual, as in coughing, it receives immediately a larger supply of blood. If a man walks several miles, more blood and lymph will go through his lung, and, consequently, in the case of a diseased lung, more poison will be swept out than if he lay quietly on a sofa during the same period of time.

Movement, therefore, determines the quantity of blood and lymph which goes through the lung; this in turn determines the amount of poison swept into the general circulation, and this again determines the task which the defensive forces have to meet. In treatment, therefore, if the bacilli are not to be allowed to spread, and the disease to extend, the amounts of rest and exertion must be carefully and constantly regulated according to the evervarying symptoms of the patient.

It follows that in all cases of consumption where the dose of poison absorbed is capable of being in excess of the powers of the defensive forces-that is, in the majority of such cases in the class chiefly affected by the Insurance Bill-constant skilled medical supervision is only possible in the institution which is usually called a sanatorium. It also follows that this constant supervision is not so essential in cases in which the defensive forces are fully capable of dealing with the poison absorbed into the general circulation.

Cases of consumption may be roughly divided into four classes.

Class I. Those patients who become infected and recover without knowing that they have been infected. In these the dose of poison absorbed is practically never beyond the capacity of the defensive forces, and so acts as a stimulant.

Class II. Those who would recover if given a holiday at the seaside or some measure of outdoor treatment. In these cases the defensive forces want assistance. The insanitary conditions, want of food, etc., under which the patient lives, diminish the capacity of his defensives forces and so enable the bacilli to make further inroads. When the patient is removed from these devitalizing conditions his defensive forces automatically become able to fight better, and to deal adequately with such doses of poison as may be absorbed. Consequently, in such cases, were we in a position to gauge the exact condition of affairs, treatment in a sanatorium would be unnecessary. This in the majority of instances we cannot do. It is the best policy, therefore, to send such cases to a sanatorium in the first place. When such supervision is possible the duration of treatment will of course be much shorter than in the case of those who properly come under Class III.

Class III. Those who need careful treatment in a sanatorium. In this class the dose of poison is generally greater than the capacity of the defensive forces, and therefore the amounts of rest and exercise to be taken require constant supervision.

Class IV. Those who are going to die from infection, whatever may be done for them. This failure is probably due to :

1. The incapacity of the defensive forces to respond.

2. The excess of the absorbed poison even in absolute rest is beyond the capacity of the defensive forces.

These conditions can be ascertained only after skilled and close observation.

It is clear, then, in the treatment of cases of consumption in which recovery is not going to occur spontaneously, the defensive forces require careful nourishment, in the shape of fresh air and good food, and, above all, the amount of rest and exertion must be carefully regulated from hour to hour.

It does not require much thought to see that, in a national campaign dealing with persons whose income is below $£ 160$, treatment in efficient sanatoriums is a vital necessity.

It is asserted that tuberculin, used in dispensaries for patients who continue to work, gives results as good or better than treatment in a sanatorium. Treatment by tuberculin in Class I or in Class II is well known to give excellent results, but so does practically any other form of treatment.. In Class III, where doses of poison are, on the whole, in excess of the capacity of the defensive forces, tubercalin cannot safely be used except under constant supervision. If the regulation of the absorption of a man's own poison-his own tuberculin-requires constant supervision, it follows that the administration of prepared tuberculin requires the same close observation.

The success of the so-called tuberculin dispensaries rests largely on the fact that Class I and Class II are chiefly treated at them. A further part of their success is due to the many instances in which the diagnosis of the presence of active disease is faulty, with the result that many persons are treated with tuberculin and labelled as cures in whom the disease has previously been arrested. The fact that the physicians attached to the hospitals for diseases of the chest send their patients to sanatoriums is a strong testimony to their usefulness; for it is much more lucrative (to the physician) to give tuberculin than to send patients to be treated elsewhere. Of the value of tuberculin there is no question. Its use is of great value, not only in Class II, but also in Class III-that is, in patients who require sanatorium treatment. We come, therefore, to the conclusion that neither sanatorium treatment nor tuberculin should be depended upon solely, but that both should be used under conditions which facilitate the closest supervision.

It sanatorium treatment has not hitherto met with universal acceptance as efficacious in a campaign against consumption, the mistrust is due to a number of causes. In the first place the majority of existing so-called sanatoriums are inefficient, and the treatment given is not " sanatorium treatment," but a treatment in an institution labelled a sanatorium, and consisting of little more than fresh air and abundance of nourishing food, but without adequate medical supervision and the necessary regulation of rest and exercise. The results obtained by these inefficient sanatoriums have been regarded by the public, and by many members of the medical profession, as the results of efficient sanatorium treatment, and have done much to discredit it. The second reason is that sanatorium treatment has been asked to do the impossible, and has been regarded in some quarters as sufficient in itself, and as a certain cure for every case of consumption. No responsible member of the medical profession, no level-headed layman, has ever regarded the treatment in this light. The sanatorium is an important link, but only a link, in a comparatively long chain. Unless it forms a part of a carefully thought out system, embracing, amongst other things, dispensaries, hospitals, homes for advanced cases and the dying, careful disinfection and after-care of patients when they leave the sanatorium, together with assistance to the breadwinner's family whilst he is under treatment, it cannot help us much to eradicate consumption. Even sanatorium treatment does not cure all forms of pulmonary tuberculosis, and we can scarcely anticipate that any form of treatment ever will prove very efficacious in advanced and long-standing disease. Is it fair to condemn sanatorium treatment because it cannot accomplish the impossible? Again, if a working man in an early stage of consumption is sent to an efficient sanatorium, there is every prospect of the disease being arrested; but, if he is allowed to return to those conditions under which he contracted the diseasehard work, bad air, insufficient food-the disease will almost certainly relapse. Is it fair, when this happens, to say that sanatorium treatment is of no avail?

The third reason is the fact that in the past the erection and maintenance of sanatoriums have cost far too much. This objection no longer holds, as, apart from the cost of land, a sanatorium of a permanent character can be erected and equipped for a little over $£ 100$ a bed. The cost of maintenance and administration should amount to rather less than $25 \mathrm{~s}$. a week per patient. The fourth reason has been the difficulty of making such arrangements for maintaining the family when the breadwinner is away, that the patient may be persuaded to go to a sanatorium early enough, and to stay long enough. Much of this difficulty, however, should be swept away by an intelligent administration of the Insurance Bill. 
Sanatorium treatment, as a link in a chain, confined to those who are capable of being cured within a reasonable period and supervised by a competent and special trained medical man with administrative capacity, is one of the most valuable offensive weapons we have to-day in our fight against consumption. We have shown that its value in the past has been obscured for several reasonsthe inefficiency of many sanatoriums, improper selection of cases, inadequate length of treatment, inadequate "after-care," and the like. In the future most of these defects should be removed by efficient administration. In the past many men did not apply for treatment because they knew there was no likelihood of it being obtained in time, as the sanatorium accommodation was insufficient for more than about 1 per cent. of the consumptive population. Under the new Act there should be much greater accommodation, and this in itself should do much to secure treatment in the earlier stages of the disease and to rehabilitate sanatorium treatment in the opinion of the general public.

(Signed) Clifford Allbutt. Lauder Brunton. Arthur Latham. William OsLer.

\section{PENSIONS FOR PROFESSIONAL MEN.}

Government officials are, generally speaking, entitled to a pension on retirement, and most important business institutions have some scheme of superannuation for their staff, but, as a rule, a medical man has no retiring allowance to look forward to after a strenuous life unless he has had sufficient foresight to provide it out of his income.

The average man who desires to set aside, say, $£ 50$ per annum to supplement his income on retirement and replace capital sunk in a practice requires the help of some system, or there is very apt to come a time when he fails to carry out his intentions.

There are two courses open to medical men who intend to save a part of their income. They can invest through the Stock Exchange, earn a remunerative rate of interest, and take their chance of appreciation or depreciation in the amount they save. To follow this plan with any degree of success it is almost essential to have some special training in finance, and a great deal of time must be spent in selecting and watching the investments made. It would, of course, be necessary to reinvest the dividends as soon as received if compound interest is to be secured. After allowing for tax, brokerage, etc., it would be hard to realize more than $3 \frac{1}{2}$ per cent. as a net yield in this way.

Let us suppose that, after allowing for income tax and brokerage, $£ 50$ per annum is successfully accumulated at the net rate of $3 \frac{1}{2}$ per cent. compound interest for twenty years, then the amount invested at the end of that period would be $£ 1,463$. In the event of death before completion of the twenty years, only the savings to date with the interest thereon would be receivable.

Under the alternative plan of effecting a pension policy with a life assurance company, the result from an investment point of view is much the same, but the responsibility and work are thrown upon the company. A pension policy, however, presents two aspects-saving and protection. That is to say, a part of every premium paid is being saved for the assured, as in a savings bank, to be returned to him at a later date with compound interest, and the other part secures protection until the pension age is reached, so that in the event of premature death the capital amount is payable in full. The benefits thus secured under a pension policy in the event of death before maturity outweigh those obtainable by ordinary investment apart from the question of security.

It would be necessary to spend more on the pension policy to produce the same result, because in the event of premature death the full sum assured with bonuses to date would become payable. To provide $£ 1,463$, or a pension of $£ 128$ (nearly $£ 210$ s. a week) at age 60 in the case of a healthy person aged 40 next birthday, a pension policy for $£ 1,060$ could be effected in a good office with bonuses at an assumed rate of about 38s. per cent. per annum, namely, $£ 403$.
The annual premium would be $£$ s. d.

Less income tax abatement at 9d. in

the $£ \quad \ldots \quad \ldots . \quad \ldots \quad \ldots$ $\begin{array}{lll}2 & 4 & 1\end{array}$

As compared with the annual saving $\begin{array}{llll}50 & 0 & 0\end{array}$

So that the cost of the cover is only $\quad \ldots \quad \begin{array}{lllll} & \ldots 6 & 11 & 8\end{array}$

This may seem a large sum to pay annually, but the diagram shows that the extra covering is considerable. Only about 70 of every 100 can expect to live to the maturing age, so that the chance of reaping a benefit is not a small one.

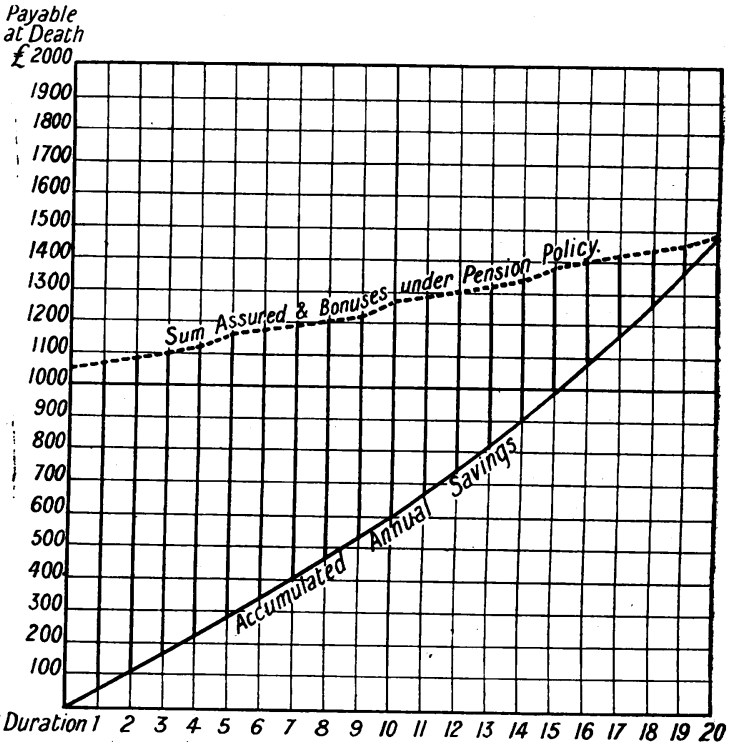

Diagram showing comparative sums payable at death under (1) With profit endowment assurance for £1,060 effected on healthy person aged 40 n.b.d. with clerical "bonus (annual premium $25815 \mathrm{~s}$. 9d.), payable at age 60 or at previous death.

In the above diagram the dotted line represents the sum assured by the pension scheme with the bonuses at the rate already mentioned, while the continuous line shows the corresponding sum in hand each successive year by the system of annual savings. The distance represented by the perpendicular line is therefore the extra amount receivable at death, which, it will be seen, starting at over $£ 1,000$, gradually diminishes during the twenty years till in the end the two results are the same.

A pension policy may fitly be described as a scientific form of saving. No trouble is involved, and there are no incidental expenses, the one important factor being the prudent selection of an office. The protection afforded during the period of saving should appeal specially to medical men. Another point not to be lost sight of is that the contract is elastic - the amount saved can be realized in a lump sum, or as a guaranteed pension, as circumstances demand. If it be desired or necessary to discontinue the annual payments, a paid-up assurance can be secured proportionate to the number of annual payments already made. Thus five payments made out of twenty secure five-twentieths of the original sum contracted for.

On such policies the Medical Insurance Committee are in a position to allow a substantial reduction off the first annual premium. Full particulars will be forwarded on application to the Secretary, Medical Insurance Committee, 429, Strand, London, W.C.

MRS. MAX BEERBOHM appeals for contributions to the Necessitous Ladies Holiday Fund, established to give sea or countryside holidays to governesses, typewriters, hospital nurses, secretaries, musicians, actresses, and ladies engaged in other professions, who, unable to provide holidays for themselves, and without the possibility of earning money in the summer months, are left behind in London exposed to the sufferings attendant on poverty. All contributions sent to Mrs. Beerbohm, at 48, Upper Berkeley Street, W., will be acknowledged. 